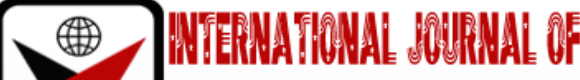

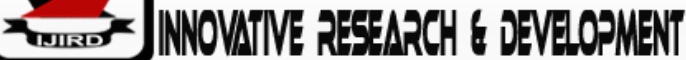

ISSN $2278-0211$ (Online)

\section{Cost Analysis of Treatment of Road Traffic Injuries among Victims at the Kenyatta National Hospital Nairobi City County, Kenya}

Zablon Anyenda Lipule
Masters Student, Department of Health Management and Informatics,
School of Public Health, Kenyatta University, Kenya
Dr. Andre Yitambe
Senior Lecturer, Department of Health Management and Informatics,
School of Public Health, Kenyatta University, Kenya
Dr. Kenneth Rucha
Lecturer, Department of Health Management and Informatics,
School of Public Health, Kenyatta University, Kenya

\section{Abstract:}

Background; Many studies have reported Road traffic injuries (RTIs) leading to fatalities of over one million victims annually and negatively impacting on health, economy and development of the society as a whole, furthermore, young men and women at their most economic age group, are highly affected by RTIs and in most cases it causing mortality and very severe morbidity due disability. With projection by the year 2030, RTIs will be ranked as the fifth cause of disability adjusted life years (DALYs) lost. There is little or no any published Evidence on healthcare resource utilization and allocations after RTIs, especially in developing countries. Africa included. Locally in Kenya road accident remains a major public health concern, with high mortality and morbidity rates reported annually.

Aim: The Main objective of this study was to analyze the total hospital Expenditure/cost related to RTI (Road traffic injury) admitted at the Kenyatta National Hospital for a period of 3 months from the start of the study.

Methods: This was a cross sectional study design; the study location was the Kenyatta National Hospital Nairobi, surgical wards and Accident \& Emergency. A sample $(n=124)$ comprising of victims admitted to the Hospital due to RTI from January 25th 2019 to $30^{\text {th }}$ May 2019. Systematic sampling was used. The independent variable was the cost of treatment while the dependent variable was direct medical treatment cost, non-medical treatment cost, productivity loss and length of stay. Primary Data collections was done through interviews of all victims admitted at the KNH through $A \& E$ and qualify as per the inclusion criteria, the victims were admitted at the surgical unit level 4,5, and 6. The data collection of direct and direct non-medical cost, was by data extraction tool, testing of the tools was done at the surgical ward. Productivity loss of the victims was calculated by use of Work Productivity and Activity Impairment Questionnaire (WPAIQ). Data was analyzed by SSPS version 22.

Results: From the study $76.6 \%$ of the road users were male, while female was $23.4 \%$. Most of injuries were lower limbs, head and upper limbs in that order. Leading injuries by mode of transport was Motorcycle at 43.5\%, pedestrian and public transport at $23.4 \%$ and $17.7 \%$. Daily bed charges and Surgery were the leading cost component followed by pharmacy. Average length of stay was 24.1 days, average medical cost was at (KSH 66,482, 642 USD), productivity loss at (KSH19, 061, USD 184) and indirect cost at KSH10, 745 USD 107). There was significance correlation between total bed charges, medical cost and productivity loss at $P=0.01$. (Cl 95\%) chi square showed linear by linear association of $P$ value of .000

Conclusion: Road traffic accident is an economic burden to individual, family and country at large, males more affected at their most economic age groups. Findings will aid policy makers in review on resource allocation. Further Motion studies on cost analysis of RTIs, over a longer period to be conducted to provide more insight on the subject.

Keywords: RTIs, RTAs cost direct medical cost, direct non-medical cost, productivity cost and length of stay

\section{Introduction}

According to WHO, global road safety report (2018), road traffic related injuries fatality More than 1.35 million victims annually and greatly affects health and development of the society as a whole, the report further points out, RTIs as the leading cause of death of among children and young adults. $90 \%$ of these incidents occur in developing countries. The burden from injuries resulting from RTIs globally is high in developing countries. Close to $5 \%$ economic loss from the GDP in low and middle income is attributed to RTAs' mortalities and morbidity. The annual costs of road traffic fatalities in 
LMICs between US\$65-100 billion, this is way above the sum received as development aid as per M. aikins et al (2016). World Bank report on 'high toll of road traffic accidents 2020' identifies the correlation between reduction in road traffic accidents and the increase in growth GDP per capita, hence the need to reduce this burden on low- and middle-income countries cannot be over emphasized, considering the weak social support in these countries. Adeloye et al (2016)," did a meta-analysis study inclusive of 39 studies done in 15 African countries, and concluded a estimated pooled rate for RTIs 65.2 / 100,000 population and a death rate of 16.6 per 100,000 population". Evidence on trends demonstrates an increase in, fatalities and injuries by 26\% and 46.5\%, between January 2015 to January 2020 (NTSA, 2020.World bank report on global road safety (2019) identifies post-crash response and trauma care as a key area of focus, a study in Kenya by Macharia et al (2007) `established that there were serious gaps related to access and quality of health care services for victims after severe road traffic injuries in the country, while another study by Matheka (2015) on commercial motorcycle drivers involved in RTAs established, that this vulnerable group of road users, accounts $2 / 3$ of the total traffic injuries in the country.

For the clarity and definition of key terms used in the study was as follows and see the conceptual framework Figure 1

- Direct Medical costs: All costs of all medical services received by the victims; for example, doctor's review, diagnostics tests, medication, day surgery fee, hospital charges among others. (M S Chaudhry 2018), (Shadcam et al,2018.

- Direct non-medical costs: These are expenses other than medical cost; for example, food for the care takers, cost of transport to and from the health facility, lodging cost for the relatives among others.Papadakaki et al. (2016)

- Productivity loss: The productivity loss of the victim is the average wages lost during the period of hospitalization or premature deaths. (Chaundry, 2018)

- Length of stay: Measure of the days victims admitted in the hospital, calculated by difference between the admission day and the day of discharge.

- Average length of stay (ALOS): is it the number of days' patients has been hospitalized over total number of admissions for that month.

\section{Methods}

\subsection{Study Design and Methods}

The study design was cross sectional. The data collection and period of study was undertaken at the KNH casualty and surgical units. The defendant variable was cost of treatment of road traffic injuries of victims admitted at $\mathrm{KNH}$, independent variables were; Direct medical cost and Direct non-medical cost, Productivity cost and length of stay.

\subsubsection{Location of Study}

Location of the study was at the KNH; which is the largest public tertiary referral and teaching hospital in the east and central Africa with a patient bed capacity of over 1000. The facility receives at least 216 road traffic victims in 3 weeks, translating to at least 10 victims daily as per hospital report. KNH is located along the Hospital Road(off Ngong Road) it approximately 4 kilometeres from CBD for Nairobi City. Kenya.

\subsubsection{Research Questions}

- What are the demographic characteristics of RTI victims at KNH?

- What are the direct and indirect medical costs of treatment of RTI victims at the KNH?

- What is the estimated productivity loss of RTI victim at KNH?

- What is the average length of stay in hospital of victims admitted with RTI

\subsubsection{Objectives}

- To describe the social demographic characteristics of RTI victims admitted at KNH

- To determine the medical cost of treatment of RTI victims admitted at the KNH

- To Estimate productivity loss of RTI victims at the KNH

- To Identify the average length of stay of RTI victims at the KNH

\subsection{Sampling Method}

Purposive sampling method was applied to select KNH as study area as the largest referral and teaching Centre, it receives a number of RTI victims for specialized treatment.

Systematic sampling method was applied to select study population, using the admission register as the sampling frame; every second patients was selected for the study only if they qualify the inclusion criteria. In the surgical ward a further review of departmental admission and discharge register was done.

The sample size will be determined through statistical computation formula illustrated in fisher et al (1998). See the flow chart below(Figure 2) inclusion criteria; All victims reviewed at KNH or are admitted post road traffic accident at the KNH casualty department and then admitted to the surgical wards level 4, level 5 and level 6. While Exclusion criteria; victims involved in road traffic accident seen at the Accident and emergency treated and discharged, victims admitted to the critical care unit, or transferred out of the hospital. 


\subsection{Data Collection and Analysis}

The Data extraction tool was tested at the KNH Level 6 surgical department on long stay patient's key adjustment made to improve the validity and reliability of the data collection tool, expert opinion was sort.

SPSS version 22 and descriptive statistics was applied to present frequencies and Percentages for categorical variables (unique individualized characteristics and body parts injured). Chi-square and $\mathrm{T}$ test was applied to demonstrate any association and correlation between the variables.

\section{Results}

\subsection{Social Demographic Characteristics}

Table 1: It demonstrates majority of the road users were of male gender at $77 \%$ and $23 \%$ female of the respondents, From the study the age group at the highest risk was $18-39$ at $75 \%$ and the least was $60+$ years The level of education of the respondents slightly over $50 \%$ of the road users sampled in the study had secondary education and the least post graduate. To understand the awareness on the insurance as pillar to move the agenda on sustainable goals on development 3 "Achieve universal health coverage, including financial risk protection, access to quality essential healthcare services and access to safe, effective, quality and affordable essential medicines and vaccines for all., the study found out only $27 \%$ of the respondents had insurance cover and $73 \%$ did not have cover.

\subsection{Occupation of the Road User}

Findings in (Table 2) over 50\% were self employed, many previous studies have identified businessman as most vulnerable group. A study in tanzania by Chalya et al. (2012) identifies most of the injuries were in self employed victims at $59.5 \%$,

\subsection{Distribution of Injuries}

Lower and upper limbs were the main regions of injuries accounting for over $50 \%$ followed by head injuries, least being chest, abdomen, thorax, and spine. As shown in (Figure 3). Many previous studies have identified fractures of upper and lower limbs as the leading region of injuries. Followed closely by head injuries.

\subsection{Type of Road User}

From the study table 3, motorcycle was leading at 43.5 percent followed by pedestrian and public transport at 23.4 and $17.7 \%$ this is in agreement with previous studies who identified the group (motorcyclist, pedestrians and public transport) with highest risk of sustaining road traffic accident injuries and fatalities

\subsubsection{Medical Cost Components}

In this study daily bed chargesover $50 \%$ of total direct medical cost this could be due to long theatre list, or some patients were onconservative management, others had septic wounds that requred, daily cleaning and treatment before surgery.Surgerywas close at 25\%. The least was labaratory cost at a mean of $2128 \mathrm{ksh}$. Total direct. From the instituionpractice labaratory test were done in preparation of theatre procedures. medical cost compared to productivity loss and indirect medical cost was at $69 \%, 20 \% 11 \%$ of total cost of injuries respectively. Table 4 shows the relations between the cost elements to medical. Table 4 shows the highest cost was the direct medical cost at (ksh, 8,243847 USD 80037 ) which was $69 \%$ of the total cost. While productivity loss at (ksh 2363600, USD 22948) which was $20 \%$ of the total cost of treatment. The least was the indirect medical cost. There was a significant correlation between total direct medical cost, Productivity loss and indirect medical cost at $\mathrm{p}$-value of 0.01 with confidence interval of $95 \%$

\subsubsection{Productivity Loss}

Figure 3 histogram, shows Effect of Injury to daily activity following road traffic accidents, with more than 40 respondents verbalizing a score of 7/10, with a mean of 7.14 and SD 1.369

\subsubsection{Length of Stay}

Shorter length of stay is key demonstration of effecieny in a hospital, and this improves the admission, transfer and dicharge management. On the other hand it cuts on costs. Of note some of the , a number of victims stayed longer as aresult of waiting for procedure, equipment for limb alignment before surgery, there aws avry long list of surgeries. This is an area the study suggest for furter review, this on the other hand will reduce risk of hospital acquired infection (HAIs). From the study the average length of stay was 24.1

\section{Discussion}

From the study Table 1, it demonstrates majority of the road users were of male gender at $77 \%$ and $23 \%$ female of the respondents. The findings are consistent with many previous studies. According WHO 2015 report on road safety concluded 3 out of 4 deaths occurs in men. Male young adults are the most vulnerable road users at increased risk of RTAs. The WHO (2018) report identifies young male at the highest risk to susatain mortality or morbidity from road accidents. Of key note males are the primary source of income of families and society at large. A study on analysis of direct medical expenses on RTI in Tabriz City in iran (Shadkam et al ,2017) males were at $68 \%$ and female $32 \%$. Another study on Magnitude of road traffic accident related injuries and fatalities in Ethiopia (Narges Shadkam, 2019) concludes Male young adults are vulnerable road users at highest risk of RTAs. In another study in south africa 
(Matiwane \& Mahomed, 2018) The majority of admissions were young males (72\%) and those aged 20-34 years (53\%). The average age of fatalities was 32 years and $82 \%$ were male. (Schlottmann, 2017) a study in malawi identifies the average age and gender at the highest risk of road traffic accident injuries. Locally $76 \%$ of road accidents victims admitted in Kenyatta National Hospital were between the ages 15 to 44 years. In Moi Teaching and Referral Hospital the study observed average age of the admitted for road traffic casualties was 30.3 (Zedekia, 2017). From the study the age group at the highest risk was $18-39$ at $75 \%$ and the least was $60+$ years, however the WHO report 2018 points out age group 15-29 years as the vulnerable group involved in road traffic accidents resulting to injuries and death. These findings are consistent with this study, as age group is within the group, similarly above 19 years old are mostly injured for entire period with a statistically significant difference $(p=0.000)$ (ramadan et al, 2017) in a study on public profile of road traffic accidents in kosovo 2010-2015.

In summary the finding of the study is on vulnerable gender, age group is consitent with previous study findings with slight variation on exact age group, but it has demostrated male and age group 18-39 years as most vulnerable to sustain RTIs and fatality. The level of education of the respondents slightly over $50 \%$ of the road users sampled in the study.

The study findings in table 2 , shows over $50 \%$ were self employed, many previous studies have identified businessman as most vulnerable group. A study in tanzania by Chalya et al. (2012) identifies most of the injuries were in self employed victims at 59.5\%, this group is always on the move, for the business group they are always moving up and down to access credit, collect revenue, buy stocks and pay their bills.

Lower and upper limbs were the main regions of injuries accounting for over $50 \%$ followed by head injuries, least being chest, abdomen, thorax, and spine. As shown in Figure 3. Many previous studies have identified fractures of upper and lower limbs as the leading region of injuries. Then followed closely by head injuries. On the contrary a study in South Africa (Matiwane\&Mahomed, 2018) found out the most commonly injured body region was the head and neck $32 \%$ followed by the lower limbs and upper limbs at $28 \%$ and $20 \%$ respectively. A study on Three-month pattern of road traffic injuries at a Naivasha Hospital level 4 Matheka (2015) observes $41.5 \%$ had lower limbs injuries followed by head injuries $35.4 \%$ The majority of RTI patients were admitted in the orthopedic wards 51\% which is consistent with findings of this study.

From the study table 4 , motorcycle was leading at 43.5 percent followed by pedestrian and public transport at 23.4 and $17.7 \%$ this is in agreement with previous studies who identified the group (motorcyclist, pedestrians and public transport) with highest risk of sustaining road traffic accident injuries and fatalities. In Kenya between 2016 and 2017 there was a 55.1\% increase of total number of registered motorcycles according to Kenya National bureau of statistics economic report (2018) the mode of transport is considered as cheap and easily accessible in cases of urban centers traffic jams. High number of motorcycles explains the high casualties from RTAs. Some of these men don't undergo an adequate training before they start to ride their bikes, while pedestrians are at risk, by not abiding to traffic rules on crossing the road, in addition reckless drivers and the public transport has been notorious in noncompliance to traffic rules these findings have been discussed in previous studies. Africa has the highest proportion of pedestrian and cyclist mortalities with $44 \%$ of deaths. In South-East Asia and the Western Pacific, the majority of deaths are among riders of motorized two and three-wheelers, who represent $43 \%$ and $36 \%$ of all deaths respectively, (WHO, 2018) A study in ethiopia (Teferi AbegazI , 2019) observed Among 123 individuals who sustained RTAs in the reference period, $21.9 \%$ were drivers and $35.0 \%$ were passenger vehicle occupants. Further, $36.0 \%$ of the victims were vulnerable road users: motorcyclists $(21.0 \%)$, pedestrians $(12.1 \%)$ and cyclists $(2.9 \%)$. The findings are consitent with 2018 WHO report on road safety and facts on road traffic injuries.

To demostrate the impact of injury to a victims daily activity of living,work productivity andactivity impairement tool was applied,only $28 \%(n=35)$ of the respodents were employed for pay, while no pay was at $72 \%$ ( $n=89)$ Effect of Injury to daily activity following road traffic accidents, with more than 40 respondents verbalizing a score of $7 / 10$, with a mean of 7.14 and SD 1.369 as shown in histogram 1 most of the respondents felt due to the injuries recovery to normal state would take longer for them to return to their normal productivity and activity.

Shorter length of stay is key demonstration of effecieny in a hospital, and this improves the admission, transfer and dicharge management. On the other hand it cuts on costs. Of note some of the , a number of victims stayed longer as aresult of waiting for procedure, equipment for limb alignment before surgery, there aws avry long list of surgeries. This is an area the study suggest for furter review, this on the other hand will reduce risk of hospital acquired infection (HAIs).

From the study the average length of stay was 24.1, which closer with (Matiwane \& Mahomed,2018) who found out the orthopaedic ward the mean LOS was 22.7 days (SD: 20.3). Of note $45 \%$ to $60 \%$ all admissions in surgical wards are victims of RTIs. (Zedekia, 2017) They also account for 75\% of the patients in the spinal injury hospital. At the KNH over 80-90\% of patient admitted at Level 6 ward had RTIs. On the other hand, in Iran the national standard length of stay in hospital was 4.1 days, as a key indicator of hospital resource consumption and one of the main reasons of high cost of hospital bed-days. In other words, from policymakers, and key players in the healthcare industry advocate for shorter length of hospital stay as a major policy to control hospital costs and demonstrate an effective and efficient use of limited hospital assupported by,(NargesShadkam, 2019).

\section{Limitation of Study}

The study was done in national referral hospital and the generability may not be applicable to other healthcare setup such, private and faith-based hospitals. There was missing information on selected cost components. There is very limited research done on costing of RTI in LMICs to include our region and Kenya, much has been done in the developed world. The productivity assessment tool needs further motions study to explore the injury and effects to activities of 
victims. The institution was using both manual and computer system at the Accident and emergency registry and hence resulting to missing information.

\section{Conclusion}

This study is a strong pillar on cost of illness studies on road traffic accident injuries especiallyin a Low income country, it provides insight for further studies on the subject. Road traffic accident is a global public health concern.Of note is a high percentatge of male victims in their productive economic ages were the most affected. Them being the key support of the families and society large. Motorcylist, pedestrian and public transport came out as the leading vulnerable group tosustain road traffic injuries, with asignificant group verbalising long term recovery period.There was a significant correlation betweeen the total medical cost productivity loss and indirect medical cost. The burden to the KNH can be evidenced by the large number of road traffic accident victims admitted in the surgical unit especia;lly the level 5 and level 6 wards.

\section{Ethical Approval}

All stages of approval were done as per Kenyatta University graduate school, Nairobi City county and national research requirement

\section{Funding}

Authors didn't receive any direct funding for this research.

\section{Abbreviations}

$\begin{array}{ll}\text { DALYs } & \text { Disability adjusted life years } \\ \text { GDP } & \text { Gross domestic product } \\ \text { HAIs } & \text { Hospital acquired infection } \\ \text { KNBS } & \text { Kenya national bureau of statistics } \\ \text { KNH } & \text { Kenyatta national hospital } \\ \text { KSH } & \text { Kenyan shillings } \\ \text { LMICs } & \text { Lower- and middle-income countries } \\ \text { NTSA } & \text { National transport service authority } \\ \text { USD } & \text { United states dollars } \\ \text { RTAs } & \text { Road traffic accidents } \\ \text { RTIs } & \text { Road traffic injuries } \\ \text { SSPS } & \text { Statistical Package for the Social Sciences } \\ \text { WHO } & \text { World health organization } \\ \text { WPAIQ } & \text { Productivity loss of the victims was calculated by use of Work Productivity and Activity Impairment } \\ \text { Questionnaire } & \end{array}$

\section{Acknowledgements}

I do appreciate my entire faculty at the Kenyatta University that made the publication of this journal successful. This through their supervision and guidance of my thesis.

\section{References}

i. Adeloye, D. et al. (2016). The burden of road traffic crashes, injuries and deaths in Africa: a systematic review and meta-analysis., Systematic Reviews, 510-521

ii. Abegaz T, Gebremedhin S (2019) Magnitude of road traffic accident-related injuries and fatalities in Ethiopia. PLOS ONE 14(1)

iii. Chalya et al (2012) Injury characteristics and outcome of road traffic crash victims at Bugando Medical Centre inNorthwestern Tanzania. 6:1

iv. Chaudry (2018) Economic Cost of Road Traffic Accidents in Twin Cities, PakistanKomal. European Scientific journal vol 14. No.25

v. KNBS (2018) Kenya National bureau of statistics economic report. KNBS.Nairobi

vi. KNBS (2020) Kenya National bureau of statistics economic report. KNBS.Nairobi

vii. Kumar, D L et al (2012). Burden of out-of-pocket expenditure for road traffic injuries in urban India. BMC Health Services Research, 12:285.

viii. M. Aikinset al (2016). Economic burden of motorcycle accidents in Ghana. Ghana medical journal, volume 45, number 4.

ix. M. Airkins. (2016). ECONOMIC BURDEN OF MOTORCYCLE ACCIDENTS IN NORTHERN GHANA. GHANA MEDICAL JOURNAL, Volume 45 Number.4.

X. Macharia,.WM et al (2009). Severe road traffic injuries in Kenya, quality of care and access. African Health Sciences, V (9) pg. 2.

xi. Matiwane\&Mahomed, (2018), Cost analysis of road traffic crashes in a tertiary hospital in Mpumalanga Province, South Africa Cogent Medicine 5: 1549800 https://doi.org/10.1080/2331205X.2018.1549800

xii. Matheka D.M et al. (2015). Road traffic injuries in Kenya: a survey of commercial motorcycle drivers. African Health Sciences, 8688, 1-9 
xiii. Nguyen,.et al (2012). The economic burden of road traffic injuries: evidence from a provincial general hospital in Vietnam. Injury Prevention, 10.1136.

xiv. NTSA (2019) accidents statistics found at

http://www.ntsa.go.ke/index.php?option=com_content\&view=article\&id=213\&Itemid= 706 accessed 18/8/2019

xv. Ramadani et al. (2017) Public Health Profile of Road Traffic Accidents in Kosovo 2010-2015 journal of medical sciences

xvi. Schlottman et al (2017). Road traffic collisions in Malawi: Trends and patterns of mortality on scene. Malawi Medical Journal 29 (4):301-305

xvii. Shadkam, et al. (2019). Direct medical costs of traffic injuries in Tabriz City archtrauma

xviii. Papadakaki et al (2016). Hospitalization costs and estimates of direct and indirect economic losses due to injury sustained in road traffic crashes: Results from a one-year cohort study in three European countries. sagepub

xix. Teferi.A (2019). Magnitude of road traffic accident-related injuries and fatalities in Ethiopia

$\mathrm{xx}$. The road traffic injuries the facts accessed from https://www.who.int/violence_injury_prevention/road_safety_status/2018/en/ accessed on 18/8/2019

xxi. WHO. (2018). Global status report on road safety. Geneva: WHO.

xxii. WORLD BANK (2017) High toll of road traffic accident Unacceptable and PreventableZedekia S (2017) Street Level Bureaucrats as the Ultimate Policy Makers. Journal of Political Sciences \& Public Affairs 5: 306.

\section{Appendix}

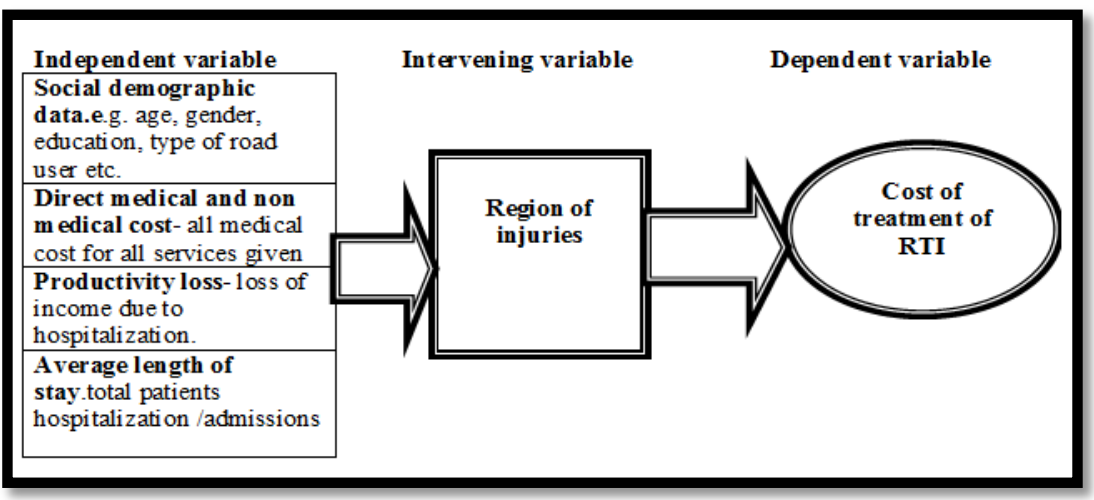

Figure 1

Source: A Adapted and Modify from Literature Review (2018)

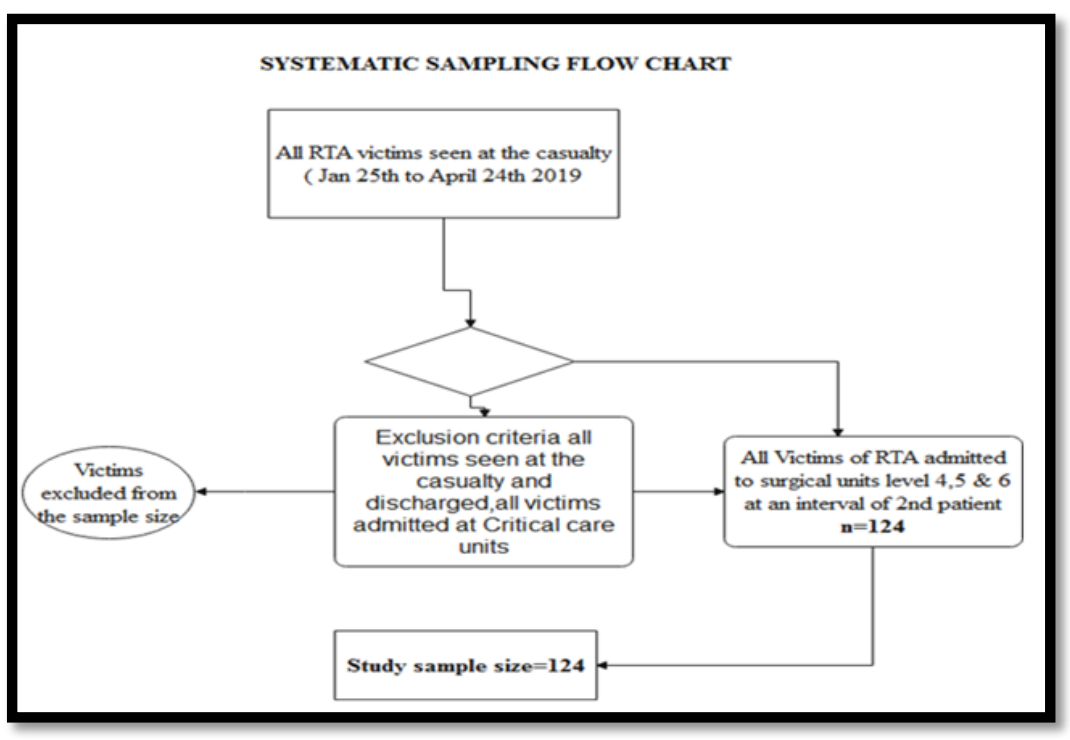

Figure 2: Flow Chart Showing Sample Determination 


\begin{tabular}{|c|c|c|}
\hline Variables & Frequency & Percentages \\
\hline \multicolumn{3}{|l|}{ Gender } \\
\hline Male & 95 & 76.6 \\
\hline \multirow{2}{*}{ Female } & 29 & 23.4 \\
\hline & 124 & 100 \\
\hline \multicolumn{3}{|l|}{ Age group in years } \\
\hline$<18$ & 4 & 3.2 \\
\hline $18-39$ & 93 & 75 \\
\hline 40-59 & 25 & 20.2 \\
\hline \multirow[t]{2}{*}{$60+$} & 2 & 1.6 \\
\hline & 124 & 100 \\
\hline \multicolumn{3}{|l|}{ Education level } \\
\hline Primary education & 42 & 33.9 \\
\hline Secondary education & 64 & 51.6 \\
\hline College education & 9 & 7.3 \\
\hline University & 9 & 7.3 \\
\hline \multirow[t]{2}{*}{ Post graduate } & 0 & 0 \\
\hline & 124 & 100 \\
\hline \multicolumn{3}{|l|}{ Insurance cover } \\
\hline Yes & 33 & 26.6 \\
\hline No & 91 & 73.4 \\
\hline Total & 124 & 100 \\
\hline
\end{tabular}

Table 1: Social Demographic Characteristics

\begin{tabular}{|c|c|c|c|c|}
\hline Occupation & Frequency & Percent & $\begin{array}{c}\text { Valid } \\
\text { Percent }\end{array}$ & $\begin{array}{c}\text { Cumulative } \\
\text { Percent }\end{array}$ \\
\hline Jua kali & 31 & 25 & 25 & 25 \\
\hline Other & 15 & 12.1 & 12.1 & 37.1 \\
\hline Self & 62 & 50 & 50 & 87.1 \\
\hline Unemployed & 9 & 7.3 & 7.3 & 94.4 \\
\hline White collar & 7 & 5.6 & 5.6 & 100 \\
\hline Total & 124 & 100 & 100 & \\
\hline
\end{tabular}

Table 2: Road User Occupation

\begin{tabular}{|c|c|c|c|c|}
\hline & Frequency & Percent & $\begin{array}{c}\text { Valid } \\
\text { Percent }\end{array}$ & $\begin{array}{c}\text { Cumulative } \\
\text { Percent }\end{array}$ \\
\hline Car & 17 & 13.7 & 13.7 & 13.7 \\
\hline Lorry & 1 & 0.8 & 0.8 & 14.5 \\
\hline $\begin{array}{l}\text { Motor } \\
\text { cycle }\end{array}$ & 54 & 43.5 & 43.5 & 58.1 \\
\hline Others & 1 & 0.8 & 0.8 & 58.9 \\
\hline Pedestrian & 29 & 23.4 & 23.4 & 82.3 \\
\hline Public & 22 & 17.7 & 17.7 & 100 \\
\hline Total & 124 & 100 & 100 & \\
\hline
\end{tabular}

Table 3: Mode of Transport 


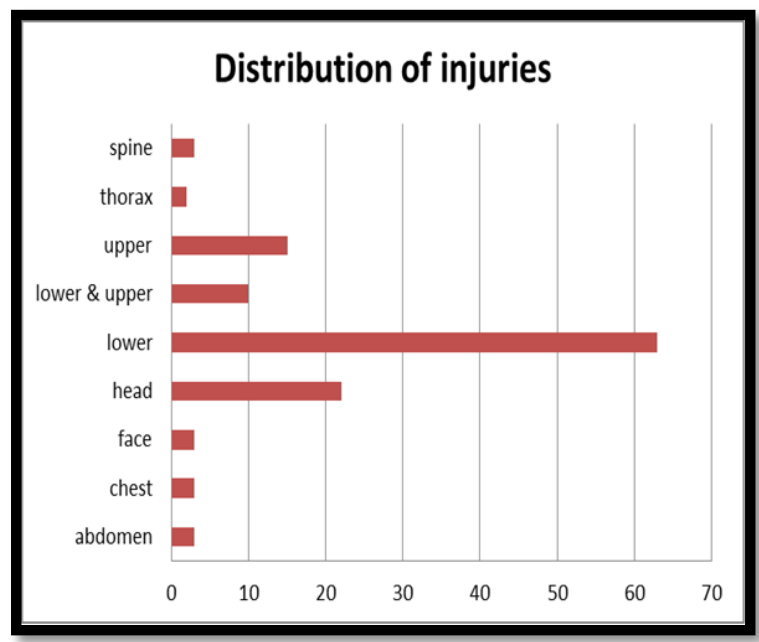

Figure 3: Distribution of Injuries by Region of the Body

\begin{tabular}{|c|c|c|c|c|c|c|}
\hline $\begin{array}{c}\text { Cost } \\
\text { Component }\end{array}$ & $\begin{array}{c}\text { Amount in } \\
\text { Ksh }\end{array}$ & $\begin{array}{l}\text { Amount } \\
\text { in USD }\end{array}$ & $\begin{array}{c}\text { \% of Total Direct } \\
\text { Medical Cost }\end{array}$ & $\begin{array}{c}\text { \% Total } \\
\text { Cost }\end{array}$ & $\begin{array}{c}\text { Mean } \\
\text { Ksh }\end{array}$ & P-value \\
\hline & $\begin{array}{c}\text { Direct } \\
\text { Medical cost }\end{array}$ & & & & & \\
\hline Surgical cost & 2113470 & 20519 & 26 & & 17044 & \\
\hline Pharmacy cost & 563194 & 5468 & 7 & & 4542 & \\
\hline $\begin{array}{l}\text { Laboratory } \\
\text { cost }\end{array}$ & 263953 & 2563 & 3 & & 2129 & \\
\hline $\begin{array}{c}\text { Diagnostic cost } \\
\text { Bed charges } \\
\text { A/E charges } \\
\text { Subtotal }\end{array}$ & $\begin{array}{c}508330 \\
4469300 \\
325600 \\
8243847\end{array}$ & $\begin{array}{c}4935 \\
43391 \\
3161 \\
80037\end{array}$ & $\begin{array}{c}6 \\
54 \\
4 \\
100\end{array}$ & $69 \%$ & $\begin{array}{c}4099 \\
36043 \\
2626\end{array}$ & 0.01 \\
\hline $\begin{array}{c}\text { Productivity } \\
\text { loss } \\
\text { Subtotal }\end{array}$ & $\begin{array}{c}\text { Cost of } \\
\text { Productivity } \\
\text { loss } \\
2363600\end{array}$ & 22948 & & $20 \%$ & & 0.01 \\
\hline & $\begin{array}{l}\text { Indirect } \\
\text { medical }\end{array}$ & & & & & \\
\hline $\begin{array}{c}\text { Indirect } \\
\text { medical cost }\end{array}$ & 1332450 & 12936 & & $11 \%$ & & 0.01 \\
\hline $\mathrm{N}$ & 124 & 124 & 124 & & & \\
\hline $\begin{array}{l}\text { Total cost of } \\
\text { treatment }\end{array}$ & 1193989 & 115921 & & $100 \%$ & & \\
\hline
\end{tabular}

Table 4: Medical Cost Components

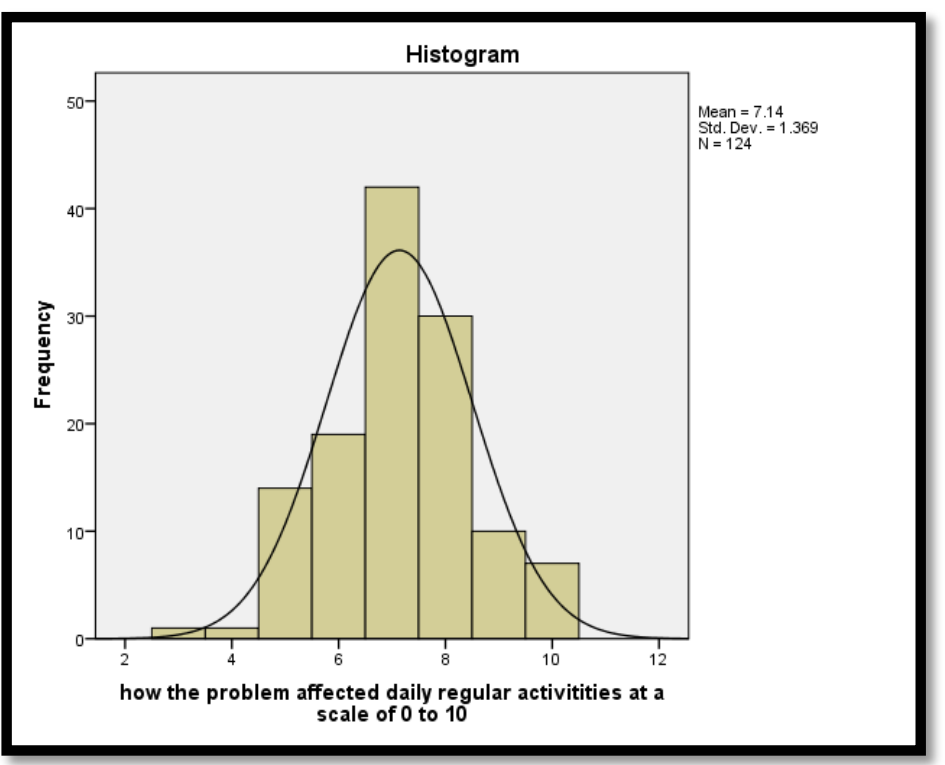

Figure 4: Showing Effect of Injuries on Daily Regular Activities 